\title{
Perspectives and ambitions of interdisciplinary connectivity researchers
}

\author{
Eva Nora Paton ${ }^{1}$, Anna Smetanová ${ }^{1}$, Tobias Krueger ${ }^{2}$, and Anthony Parsons ${ }^{3}$ \\ ${ }^{1}$ Chair of Ecohydrology, Institute of Ecology, TU Berlin, 10587 Berlin, Germany \\ ${ }^{2}$ IRI THESys, Humboldt-Universität zu Berlin, 10099 Berlin, Germany \\ ${ }^{3}$ Department of Geography, University of Sheffield, S10 2TN, Sheffield, UK
}

Correspondence: Eva Nora Paton (eva.paton@tu-berlin.de)

Received: 24 August 2018 - Discussion started: 10 September 2018

Revised: 29 December 2018 - Accepted: 14 January 2019 - Published: 29 January 2019

\begin{abstract}
The article reviews research perspectives and ambitions of connectivity scientists in order to facilitate and improve joint connectivity research efforts across disciplinary boundaries. The assessment of four very different viewpoints (pragmatic, conceptual, epistemological and ontological) on connectivity signifies the diversity of thought and practice in the connectivity community and calls for a structured way to ensure mutual understanding in collaborative settings. The shared mental model approach is introduced with an exploratory case study as a way to overcome persistent barriers in understanding by identifying gaps and overlaps of individual researchers' perspectives and knowledge that should help improve collaboration in this interdisciplinary environment.
\end{abstract}

\section{Introduction}

Connectivity research has received increasing attention in recent research agendas and discussions involving scientists from across the entire realm of disciplines, such as ecology, geomorphology, neurosciences, social network science, system biology and engineering (e.g. Manjunath and Mohan, 2007; Bracken et al., 2013; Parsons et al., 2015; Stam et al., 2016; Poeppl and Parsons, 2017). Connectivity has been used to explain functioning of complex systems, which consist of changing components forming the emergent behaviour of the whole system together (Turnbull et al., 2018). Connectivity has proven to be a particularly valuable concept in both research and management of rainfall and runoff responses (Tetzlaff et al., 2007), soil erosion (Bracken and Croke, 2007; Bracken et al., 2015), and sediment management in rivers
(Fryirs et al., 2007). Connectivity may be defined as the degree to which a system facilitates the movement of matter and energy through itself; it is an emergent property of the system's state (Connecteur WG 1, 2018). For this study, we use the term connectivity with regard to research in water, land and vegetation systems where the "movement of matter" refers to fluxes of water, sediment, contaminants or animals.

The intrinsically interdisciplinary (interactions among academic disciplines) and transdisciplinary (interactions between academia and non-academia) aspects of connectivity research create a stimulating but demanding arena. At the same time, communication barriers may severely limit the success of integrated projects (Thompson Klein, 2005). Communication barriers already start with the definition of basic connectivity terminology, since concepts and their application evolved largely within disciplinary boundaries (Turnbull et al., 2018). Separate development of many connectivity methodologies and definitions can be observed even among natural-science disciplines (e.g. hydrological connectivity by Bracken and Croke, 2007; Wainwright et al., 2011; Bracken et al., 2013; geomorphological or landscape connectivity by Brierley et al., 2006; Fryirs et al., 2007; or ecological connectivity by Brooks, 2003; Baguette et al., 2013). Through the interdisciplinary exchange of methods and approaches, there is now a pull towards cross-fertilisation among different disciplines (e.g. EU COST Action ES1306 with $>230$ members from 36 countries; Connecteur, 2018). However, moving from a plethora of case studies and a multiplicity of definitions and methodological approaches to more generic, comparable research and coordinated, theory-guided experiments might be severely hindered if participating sci- 
entists are not aware of how disciplinarily embedded viewpoints might influence thinking about and researching connectivity phenomena.

To illustrate these different mindsets, let us consider a simple example that might emerge when scientists interested in connectivity discuss "the effect of vegetation type on water flow": what snapshot image (or mindset) do you see in front of your inner eye when you start discussing it?

Figure 1 depicts images of four very different mental snapshots of scientists involved in this hypothetical discussion (which is informed by a real encounter between two such scientists): (a) that of a plant ecologist who visualises connectivity as the root network and water bridges connecting the root to soil grains (e.g. Neumann and Cardon, 2012; Prieto et al., 2012); (b) that of a hydrologist who thinks about the type and spatial layout of vegetation in floodplains, which influence water pathways and damages during a flood event; (c) that of an erosion scientist referring to vegetation patches and rill networks that enhance or inhibit water flow and erosion and associated degradation processes on the land surface (Mueller et al., 2007); and (d) that of a geomorphologist whose mental snapshot depicts the effects of vegetation on thresholds for channel initiation, drainage density and landform evolution (e.g. Istanbulluoglu and Bras, 2005).

When talking about process descriptions, model set-up, related fieldwork, timescales and uncertainty, it might take the four scientists a while to notice that the conceptual ideas of their systems are very dissimilar. Although, in dialogue, such a misunderstanding might be overcome, our experience suggests that in large interdisciplinary groups this process might take considerable time and potentially cause frustration, thereby restraining future work.

Godemann (2011), among others, illustrated that scientists are frequently unaware of the knowledge and expertise present in neighbouring disciplines or might be unable to relate it to their own knowledge. This is due to the historically disparate origins and developments of the philosophies, concepts and methods of disciplines. Yet, successful communication, integration of interdisciplinary knowledge and crossfertilisation among different disciplines, which is demanded by the complexity of the connectivity research agenda, arguably depend on the willingness and ability of the scientists to share their knowledge efficiently and to listen to others. In organisational science, the concept of shared mental models was developed (Smith-Jentsch et al., 2008; Jones et al., 2011) in order to develop a shared vision for how to proceed on joint tasks, to anticipate one another's needs and actions by understanding different conceptualisations of how a system works, to engage in more efficient searches for information and solutions, and to jointly interpret cues in the environment. In management, shared mental models have been found to be an effective way to explore the link between how people think about and how they interact with their world (Lynam and Brown, 2012; Lynam et al., 2012; Fig. 2). Shared mental models have been applied widely to compare percep- tions among stakeholders (Hare and Pahl-Wostl, 2002; Kolkman et al., 2005; Douglas et al., 2016; Gibson et al., 2016; Prager and Curfs, 2016). We believe that working towards a shared mental model of connectivity can considerably improve interdisciplinary communication and joint efforts and may even advance novel research directions (Cilliers et al., 2013). However, we should not expect these innovations to be simply a matter of smooth integration of mental models. Conflicts between research philosophies, concepts and methods can be productive for a research field, even if (or indeed because) they are not resolved (Krueger et al., 2016). In any case, differences and conflicts in mental models require explication.

Hitherto, no study on research perspectives of active connectivity scientists has been undertaken. Therefore, in this study we aim to review differences in common research perspectives on connectivity and to elucidate individual ambitions of connectivity scientists, which (as demonstrated in Fig. 1) can together considerably influence interdisciplinary communication and joint efforts in interdisciplinary research. The findings of this article comprise the outcome of a thinktank meeting of Working Group 5 (Connectivity and Society) of the EU COST Action 1306 Connecteur - Connecting European Connectivity Research in Berlin in April, 2015 (Connecteur WG 5, 2016) - and are intended to improve future research on water and land management issues.

\section{Research perspectives on connectivity}

Different scientists have different aspirations; the challenge arises when they assume a shared understanding of their research perspective, which often results in confusion and unintentional miscommunication (Bracken and Oughton, 2006). This is especially so in an interdisciplinary environment such as the connectivity community where crossfertilisation carries a large potential for scientists to improve their research practises using knowledge from beyond their own discipline. However, very different motivations exist to do this, and it is often not clear what a scientist intends to achieve by applying the knowledge of connectivity methods such as indices, modelling approaches or field designs from neighbouring disciplines.

Öberg (2011) identified four different perspectives that are common in environments where people deal with the interactions of human and natural systems while working across disciplinary boundaries: the pragmatic, conceptual, epistemological and ontological perspectives. While we acknowledge that other terminologies and classifications are possible, in the following we review Öberg's (2011) four perspectives in regard to their interdisciplinary applicability to connectivity research. 
(a)
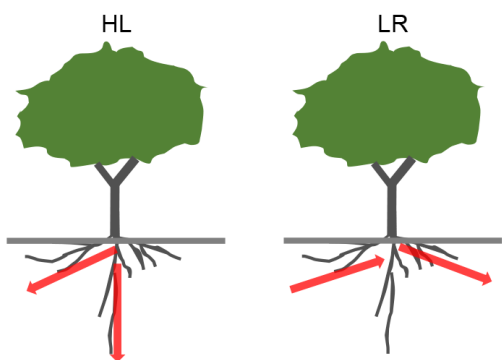

(c)

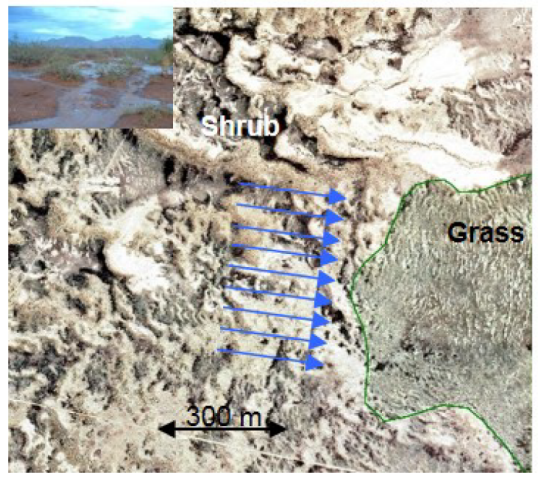

(b)

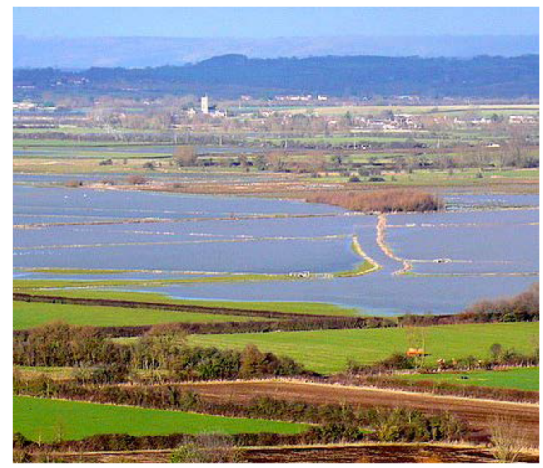

(d)

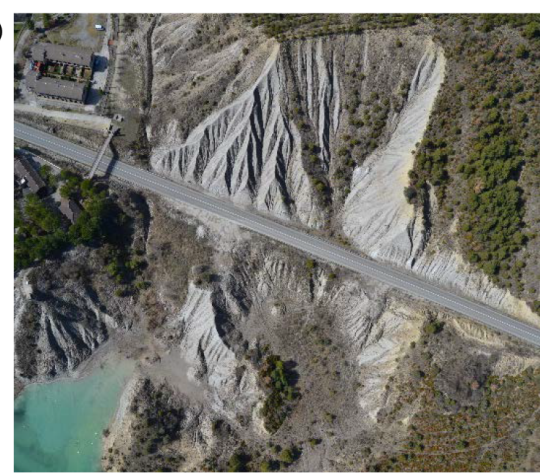

Figure 1. Example of connectivity snapshot images of scientists discussing the effects of vegetation type on water flow. (a) Plant-ecological snapshot: different types of hydraulic redistribution (HR); hydraulic lift (HL), the most commonly observed type of HR, takes place when shallow soil layers are drier than deep layers, and lateral redistribution (LR) is the horizontal redistribution of soil water between soil layers at the same depth but with different water potentials (after Prieto et al., 2012). (b) Hydrological snapshot: flooding on West Moor, Somerset (Mykura, 2018, creative commons licence). (c) Erosion snapshot: water and erosion modelling across a vegetation boundary from a shrubland (top, marked shrub in the picture) with high hydrological connectivity to a grassland (bottom left) with low hydrological connectivity (Mueller et al., 2007) and arrows indicating the direction of water flow. (d) Geomorphological snapshot: effects of vegetation (and anthropogenic structures) on channel initiation, drainage density and landform evolution (Vericat, 2015, with permission).

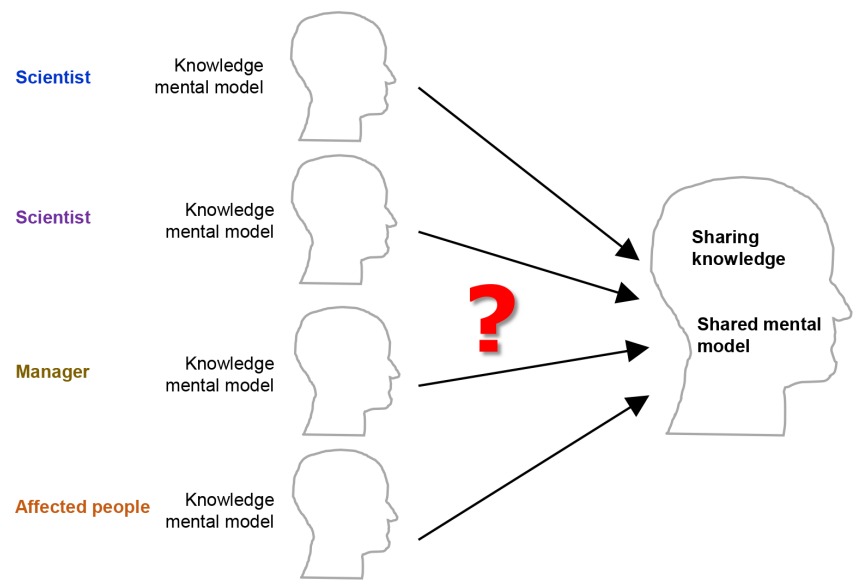

Figure 2. Sharing knowledge through shared mental models.

1. Pragmatic perspective: to solve a practical academic problem. Hydrologists saw the similarity between a rainfall-runoff equation for catchments and the waiting of customers in a serving queue (see for exam- ple Harel and Mouche, 2014). Subsequently a hydrologist used a model from queuing theory, which was developed in operational research for telecommunications using a simple probabilistic approach or map equations describing queue length and waiting time. Harel and Mouche (2013) applied a queuing model to study connectivity features of rainfall-runoff processes along hillslopes using corresponding terms of the waiting time of queues for the separation of water flow. Although these researchers were perhaps initially motivated by curiosity in exploring the parallels of the two applications, this example illustrates how disciplines may borrow methods, theories and models from other disciplines to enhance their toolbox in proceeding with a certain research objective (Öberg, 2011). The pragmatic approach is probably the most common one in current connectivity research and strives towards the crossfertilisation of methods from different environmental disciplines, as established by the EU COST Action Connecteur (Connecteur, 2018). However, one has to be aware that this approach holds the danger of severe mis- 
judgement when using methodologies without understanding the underlying theories, assumptions, boundary conditions and resulting consequences. An example might be engineering the application of erosion models reproducing sheet erosion (such as USLE) to assess reservoir infilling by sediments in regions where most of sediment originates from gully erosion.

2. Conceptual perspective: to contribute to a new or emerging field. Connectivity research can be viewed as forming a new, emerging science field, which goes beyond the traditional disciplinary boundaries of single environmental disciplines such as hydrology, ecology or geomorphology and even stretches to current efforts in life science research and beyond. The establishment of new theories with novel concepts for any connected systems is at the heart of this perspective, which include, for example, the study of brain network organisation and function connectivity in neuroscience (Stam et al., 2016); social networks for opinion formation in social science (Grabowski, 2009); interacting, adaptive or self-organisational sensor or power networks in electrical engineering (Manjunath and Mohan, 2007); or connectivity index tools for big data analysis. The setting up of overarching theories requires a deep understanding of the core of existing connectivity methods and concepts in a range of science disciplines (e.g. Callagero and Ursino, 2018). The conceptual perspective, therefore, has the great potential to identify much more innovative applications of knowledge than just borrowing single methods as described above, but this will only be possible if deep communication and the exchange of information between disciplines are ensured.

Scientists adopting the conceptual perspective are likely to belong to a specific speech community associated with their discipline. In this context, Bracken and Oughton (2006) called for a critical, reflexive awareness of how scientists use language in their interdisciplinary work as a crucial step towards establishing a shared language. For example, they showed that differing usage and understanding of common terms such as "dynamic" was rooted in differences between disciplinary use of term and their everyday meaning. The background of the research group, research approach, geographic setting of the study, language and national scholarly background (Bracken et al., 2013; Smetanová and Dąbrowska, 2009) can further influence understanding of common terms and development of connectivity concepts in interdisciplinary and international groups.

3. Epistemological perspective: to analyse the way in which disciplinary structures cause problems. With an epistemological approach, the focus of study is knowledge generation itself, e.g. through analysing the implications of studying, understanding and describing a problem from particular disciplinary viewpoints (Öberg, 2011). The comparison of particular disciplinary viewpoints (from biology, neuroscience, geomorphology, social network science and ecology) on the definition of the fundamental unit of connectivity, structural and functional connectivity; emergent behaviour of complex systems; and measuring connectivity using epistemological approach was provided recently by Turnbull et al. (2018). Connectivity research further opens an interesting arena for interdisciplinary scholars to study the practices of interdisciplinary environmental projects and analyse how and to what extent the involved disciplines connect their knowledge with each other and with society. Essentially, this article attempts to use an epistemological perspective on connectivity research to understand how multiple mental models of connectivity scientists differ and the measures that might be necessary for a shared understanding to be gained.

4. Ontological perspective: to analyse the consequences of societal perceptions of an environmental issue. The way environmental issues are described guides our understanding and perception of the environment (Öberg, 2011), thereby reinforcing how environmental issues "are" (in an ontological sense) through particular management responses. "Connectivity" is a term that is currently widely used in the hydrological and ecological sciences, but scientists actually have very limited knowledge on the perceived relevance of connectivity (or lack of thereof) for water and land managers and policymakers outside academia. An example of connectivity perception outside academia was given by the Unites States Supreme Court (547 US 715 - 2006) case Rapanos vs. United States. The legal notion of a "significant nexus" was introduced by US Supreme Court Justice Anthony Kennedy and was further criticised while acknowledging that tangible evidence of water, sediment, chemical and biological connectivity needs to be obtained before specific wetlands, lakes, riparian areas and other water bodies are protected by the federal government.

We claim that if the concepts of connectivity methods both theoretical aspects (e.g. Bracken et al., 2015; Cossart et al., 2018; Keesstra et al., 2018) and practical aspects regarding monitoring the design, model and index implementation adapted to planning applications (e.g. Clauzel et al., 2013; Foltête et al., 2015; Tannier et al., 2016; Ahlmer et al., 2018) - have not yet fully entered the mindset of water and land managers, they cannot understand how to monitor, model and subsequently manage environmental problems. But how relevant is connectivity to water and land managers? This question can only be answered by studying the perceived relevance 
of connectivity issues by stakeholders across the environmental sector. Perceived relevance of connectivity seems to be rooted in the experience and everyday challenges of water and land managers and contributes to heterogeneities in the potential to manage connectivity and apply methods adapted for management purposes (Smetanová et al., 2018, questioned 85 stakeholders in 19 EU countries). The studies of perceived relevance of connectivity may radically alter (in an ontological sense) the nature of connectivity as a research problem (Freeman et al., 2007; Nadeau and Rains, 2007; Leibowitz et al., 2008; Golden et al., 2017; Ali et al., 2018).

The four very different viewpoints applied to connectivity research signify the diversity of thinking in the connectivity community and call for a structured way for scientists from different viewpoints to communicate with each other. It suggests, for example, that scientists with a pragmatic and an ontological perspective might develop serious communication and understanding problems if they start working together on connectivity issues. The next section will present the results of our mental model elicitation as a way forward.

\section{Principles of mental models}

The first step to enhance mutual understanding in a group gathered around a specific research concept such as connectivity is to be aware of the different individual mental models that exist in that group. Mental models are closely linked to different research philosophies, concepts and methods, as they represent how people understand the world around them; they are the internal, cognitive representations of the external system. Or in other words, mental models are specific mental representations of information about reality (Pahl-Wostl and Hare, 2004). Our mental models are shaped by our previous experience and, in turn, shape our behaviour and approaches for reasoning, solving problems and carrying out tasks (Lynam and Brown, 2012). Mental models allow human beings to survive and act in a complex world (PahlWostl and Hare, 2004), though for the most part they are incomplete representations of reality and are often inconsistent among people - which is arguably one of the key reasons for understanding and communication problems in interdisciplinary research groups.

As we cannot directly access other people's thinking, a process of elicitation is used to encourage a person to externalise her or his mental model (van der Bossche et al., 2011; Jones et al., 2014). Mental models can be elicited to explore the similarities and differences in understanding of a specific concept, e.g. regarding connectivity, in order to improve understanding and communication among scientists from different disciplines. The majority of elicitation techniques are based on the assumption that an individual's mental model can be represented as a network of concepts and relations
(Jones et al., 2011). Methods for eliciting mental models comprise oral methods, such as textual analysis and inferences from interview data or questionnaires (see e.g. Carley, 1997) and visual methods using diagrammatic interview techniques that let a person externalise their mental model through the graphical representation of concepts and interactions, e.g. as a mind map (e.g. Kearney and Kaplan, 1997; see also Mohammed et al., 2000, for an excellent review on elicitation methods).

\section{Mental models of connectivity researchers: a case study}

\subsection{Methods}

There are surely as many mental models of connectivity research in academia as there are scientists working on connectivity issues, but some will be more similar than others. To begin to explore the range of existing mental models and to pilot the elicitation approach, we elicited the mental models of a small sample of 13 connectivity scientists from across the environmental, natural and geosciences during a think-tank meeting of Working Group 5 of the EU COST Action 1306 Connecteur - Connecting European Connectivity Research in Berlin, April 2015 (Connecteur WG $5,2016)$. The participants' expertise covered a broad range of environmental sub-disciplines, including (landscape) ecology (three scientists); hydrology and terrestrial ecohydrology (three scientists); geomorphology and soil science (four scientists); and geography, sustainability science, environmental management and social science (four, summarised as interdisciplinary scientists) from six EU countries; five of them were females, and eight were males. One or more of based methodological approaches - theory, field methods, spatial connectivity indices (e.g. Ludwig et al., 2007; Cavalli et al., 2013) and modelling - were applied by participants.

We used a mixture of visual methods in group discussions and a textual approach in the form of paired, semi-structured interviews to elicit the mental models. The semi-structured interviews were carried out over an average duration of half an hour (Table 1). The group discussion was moderated by the leading author, and a protocol was noted by an assistant with scientific background. Written statements were coded by the lead author according to 10 attributes of connectivity research (Table 2). The coded attributes were combined with four research perspectives described in Sect. 2 to create four stylised profiles of a researcher (colour bands in Fig. 3). The individual coded answers of each researcher were compared with these theoretical profiles. Individual research profiles were further grouped into types of profiles (A-E in Fig. 4), and the overlap between them was analysed.

The results of the elicitation process are presented here as an explorative case study to illustrate how a mixed group can identify overlaps and differences in mental models, thus il- 
Table 1. Questions of the paired, semi-structured interviews.

1. What interests you in connectivity research?

(a) Why, in general?

(b) Theory, field studies, indices, modelling, transdisciplinarity

(c) Other categories

(d) Why are you specifically interested in [connectivity modelling] and not [connectivity indices] (replace [ ] accordingly)?

2. Why do you think communicating connectivity is important?

(a) Do you mainly think about communicating within disciplines, across disciplines or outside academia?

(b) Do you have experience in science communication?

3. Why do you interact with other disciplines within or outside academia?

4. Which kind of regions and/or compartments do you carry out your connectivity research for and why are they important?

5. What can you show to illustrate your connectivity research, e.g. computer or conceptual models, field data sets, GIS applications, or observational evidence in resource management? Please make a screen shot, if possible.

6. Discipline, stage of research, gender

Table 2. Elicited attributes of connectivity research.

\begin{tabular}{|c|c|}
\hline Attribute & Description \\
\hline Discipline & Geosciences, hydrology, ecology, geography, environmental sciences, social sciences \\
\hline Research perspective & Pragmatic, conceptual, epistemological, ontological (see Sect. 2) \\
\hline Reflectivity & $\begin{array}{l}\text { Regarding research ambitions and perspectives, evaluated with a diagrammatic scale examining } \\
\text { the extent to which the scientist was previously aware of her or his own research perspective }\end{array}$ \\
\hline $\begin{array}{l}\text { Number of thematic } \\
\text { emphases }\end{array}$ & Dryland hydrology, sediment transport, landscape evaluation, plant-soil interactions, etc. \\
\hline $\begin{array}{l}\text { Type of geographical } \\
\text { locations }\end{array}$ & One geographical setting, more than one setting, no specific setting, any or no setting, etc. \\
\hline Type of modelling & $\begin{array}{l}\text { No modelling, pattern (e.g. of soil moisture or vegetation pattern) or flux (e.g. water or sedi- } \\
\text { ment discharge) modelling, simultaneous pattern-flux modelling, large-scale modelling such as } \\
\text { producing risk maps for flooding or drought, modelling of human-environment interactions }\end{array}$ \\
\hline Type of field studies & $\begin{array}{l}\text { None; measurement of either patterns or fluxes; both simultaneously, in combination with tracer } \\
\text { methods; large-scale monitoring of land, water and river attributes; conducting of interviews to } \\
\text { assess the perceptions of stakeholders on a specific water or land management issue }\end{array}$ \\
\hline $\begin{array}{l}\text { Extend of } \\
\text { interdisciplinarity }\end{array}$ & Mono- to interdisciplinary \\
\hline $\begin{array}{l}\text { Extend of } \\
\text { transdisciplinarity }\end{array}$ & Purely academic to transdisciplinary \\
\hline $\begin{array}{l}\text { Basic unit of } \\
\text { connectivity }\end{array}$ & $\begin{array}{l}\text { Extent to which scientists were able to specify what exactly they would measure, model or anal- } \\
\text { yse, e.g. a specific flux such as water (in } \mathrm{L} \mathrm{s}^{-1} \text { ) or matter }\left(\mathrm{kg} \mathrm{s}^{-1}\right) \text {; a combined unit describing } \\
\text { the degree to which a system facilitates the movement of matter and energy; some participants } \\
\text { answered that they were not aware of a unit or that their conceptual framework did not include } \\
\text { the concept of a basic unit for connectivity }\end{array}$ \\
\hline
\end{tabular}


lustrating the path towards developing a shared mental model in order to enhance the performance of an interdisciplinary research project, in general, and for connectivity projects, specifically.

\subsection{Results}

The results of the questionnaires are graphically represented in Fig. 3. Figure 3 represents the elicited mental models of the 13 connectivity scientists (black lines), according to coded attributes collected by the lead author (Table 2). Four research perspectives described in Sect. 2 were used as a baseline to structure differences and similarities of the 13 mental models. Four stylised research profiles representing four research perspectives are represented by colour bands in Fig. 3. The yellow band comprises research with a single thematic emphasis and setting, no inter- and transdisciplinarity and reflectivity and one specific flux as a basic unit for modelling and field studies. The orange band signifies several thematic emphases and study locations, a mixed basic unit of matter and energy which is employed in both conceptual modelling and field work approaches, and a fair degree of inter- and transdisciplinarity (without it being the main focus) and reflectivity. The red band represents multiple emphases but no specific setting, where inter- and transdisciplinarity becomes the main focus and where the basic unit is not known when dealing with large-scale modelling or national monitoring networks. The purple band is somewhat disconnected and identifies an emphasis on general societal aspects of connectivity research within any setting, with very strong inter- and transdisciplinary and reflective attitudes in which a basic connectivity unit does not play a role.

The resulting tangle of individual research profiles (black lines) apparent in Fig. 3 signifies high diversity and thus a high degree of difference in the mental models of the $13 \mathrm{sci}$ entists. Four of the 13 profiles follow one of the four stylised colour bands (as explained above), and the remaining nine profiles exhibit attribute combinations from two, in two cases from three neighbouring band types. The number of interviewees is too small for generalisation, but even with only 13 participants, the diagram shows that there are not four "standard types of connectivity researchers". At the same time the diagram shows that the groupings of the profiles are not completely random either, as overlapping or complementary individual profiles existed in the group.

The elicitation process of this case study has demonstrated the apparent similarities and dissimilarities in approaching connectivity research. This will now be discussed in terms of a shared understanding or a shared mental model.

\section{Discussion: towards shared mental models in connectivity research - knowledge gaps and overlaps}

Shared mental models refer to the overlapping mental representations by members of a group or, in other words, the meta-knowledge that goes beyond the various research and personal perspectives of individual team members (van der Bossche et al., 2011; Godeman, 2011). Our study demonstrates similarities and differences in mental models of connectivity researchers, which was apparent even in a small group. Carley (1997) suggested three major areas of contention in shared knowledge production, (i) the uniformity of sharing - whether knowledge must be uniformly shared by group members; (ii) degree of sharing - how widely the knowledge must be shared; and (iii) awareness of sharing whether the individual group members must be aware that the group's mental model is shared. According to group discussions during the workshop, we consider the last area the most important for a truly interdisciplinary research field such as connectivity science.

How then can we achieve a shared understanding or a shared mental model in interdisciplinary connectivity research? According to van der Bossche et al. (2011), it appears insufficient to attempt knowledge convergence solely based on conversation or by simply paying attention and acknowledging a contribution as we usually do in keynote lectures and workshop presentations during scientific meetings. Instead, van der Bossche et al. (2011) call for active interactions; three of such efforts documented in this study will be discussed here in turn.

First, co-construction of specific or general connectivity terminology is required, even if parts of the group might consider it a waste of time. On this basis, co-construction of knowledge can be understood as the group members' attitude towards knowledge which allows them to query it. Challenging each other's views, definitions and divergences with respect to a specific aspect of their joint work might become essential - especially given that no coherent definition for connectivity itself has been agreed upon (see list of references with possible definitions in the introduction section). For example, in our group discussion we began to co-construct knowledge regarding the concept of a basic unit of connectivity, a concept that some scientists had a very clear opinion on (e.g. discharge of water in $\mathrm{m}^{3}$ day $^{-1}$ ), whereas some were not aware that there was a basic unit, and others rejected the idea of a basic unit of connectivity altogether; in their research, the focus lay on the linkages of multiple human-environment aspects where a basic unit concept would only constrict their perspectives (see Turnbull et al., 2018, for a review of basic units of connectivity).

Second, constructive conflicts may help to improve group communication, e.g. by unravelling different points of view (De Dreu and Weingart, 2003; Krueger et al., 2016) that affect how interdisciplinary group approaches open questions in connectivity science. Although the colour contours 


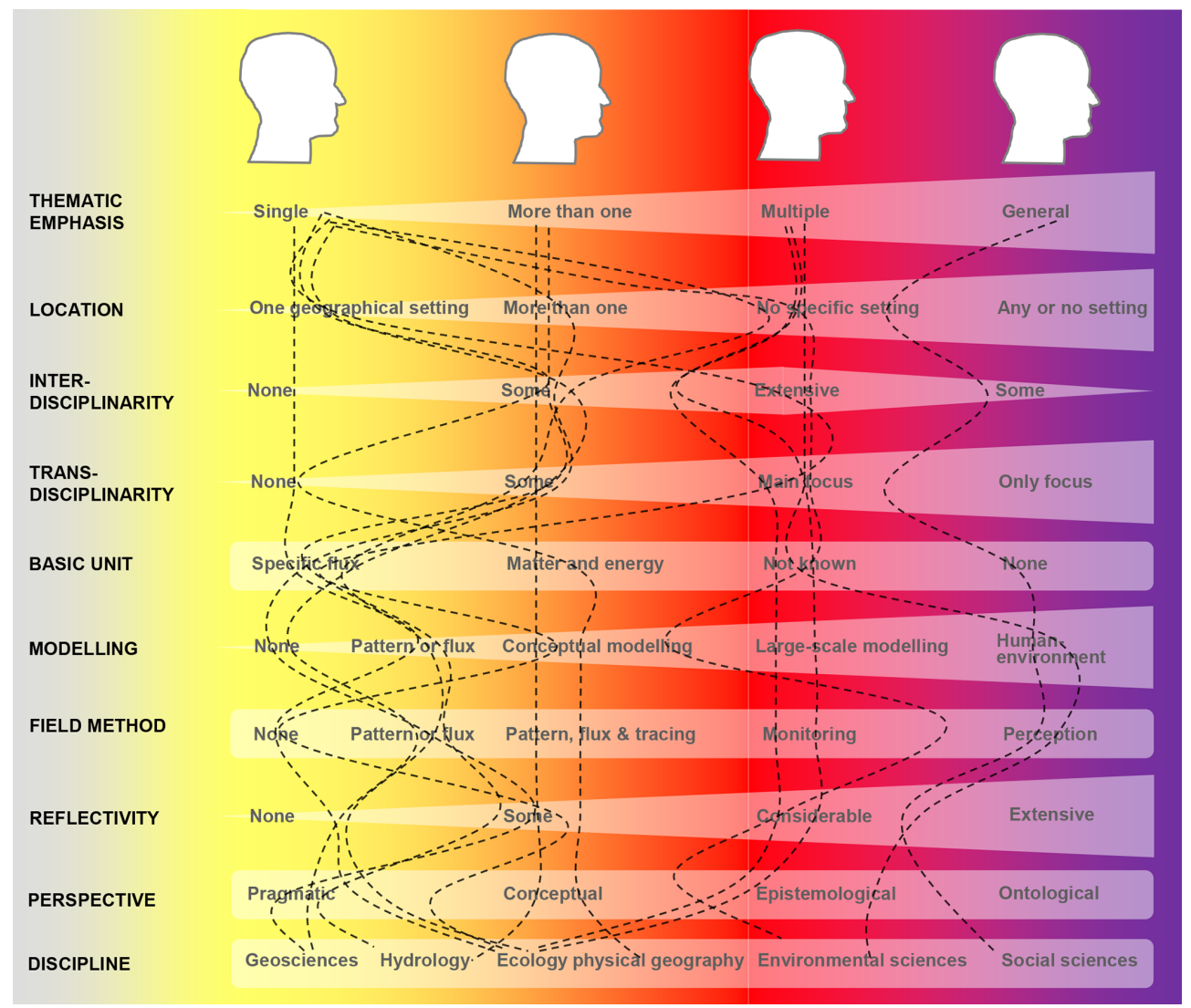

Figure 3. Individual mental model profiles of 13 scientists active in connectivity research. Individual mental model profiles (lines) plotted against elicited attributes of four stylised research perspectives (pragmatic - yellow; conceptual - orange; epistemological - red; ontological - violet) after Öberg (2011). The representation of interdisciplinarity is two-sided by referring to small-to-extensive interactions between different natural-science disciplines on the left side of the graphic ("None" to "Some") and between natural and social sciences in the middle and on the right side of the graphic ("Extensive" to "Some").

of Fig. 3, representing Öberg's (2011) four research perspectives (pragmatic - yellow; conceptual - orange; epistemological - red; ontological - violet), were only reproduced by the individual profiles of the scientists' mental models to some extent (lines in Fig. 3), it was possible to identify certain groupings of profiles around one of the four perspectives. For a constructive conflict, scientists need to be aware of the mere existence of other research perspectives; based on our group discussion, we claim that this awareness normally does not exist among connectivity researchers. Nonexisting awareness about other research perspectives might be an inherent trait of the natural sciences, since their education does not emphasise different research positions as done by the interpretative social sciences. The process of constructive conflict will expose, among other things, what the intentions of scientists are to use techniques from neighbouring disciplines. When one research tradition opposes the methods of another, a window of opportunity for reflection and improvement of one's own research tradition opens. Though when cross-fertilisation in connectivity research is attempted without a clarification of existing (parallel, convergent or di- vergent) research perspectives, any further discourse might quickly become both patronising and frustrating.

Third, the process of building a shared mental model (methods in Sect. 4.1, results in Sect. 4.2) can be supported by a detailed interpretation of overlaps of individual profiles, and lacks thereof, on the basis of Fig. 3. In our case study, 13 profiles (black lines in Fig. 3) could be grouped into five profile types (A-E) in Fig. 4. The five profile types A-E are further represented by colour shading of the vertical bars (corresponding to colour bands in Fig. 3). Colour shading of the bars (A-E) contains information as to whether a profile type exhibits attributes which were associated with only one of the four stylised research perspectives (pragmatic - yellow; conceptual - orange; epistemological - red; ontological - violet; A-B in Fig. 4) or with mixed perspectives (C-E in Fig. 4). Grey and shaded grey vertical bars represent the overlap between attributes of profile types. For the yellow (pragmatic, A) and red-violet profiles (epistemologicalontological, D) paired in Fig. 4 literally no overlaps exist in their mental models of connectivity research. For the other two paired profiles (A and B and D and E), several overlaps 


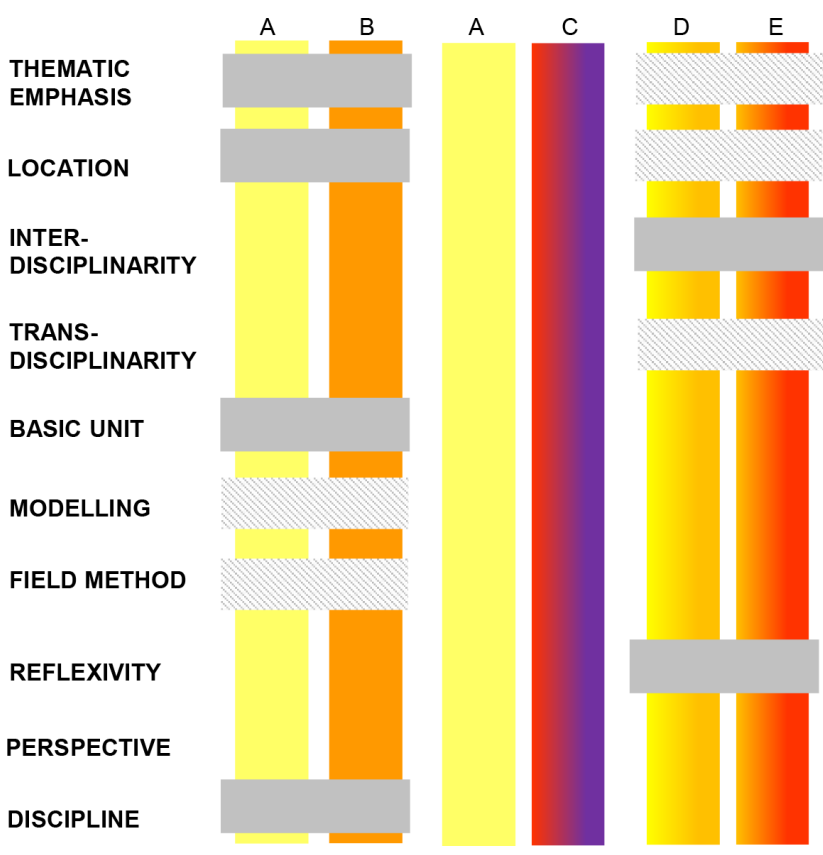

Figure 4. Graphical representation of potential mental model overlaps between pairs of stylised types of connectivity scientists. Stylised types of connectivity scientists (Fig. 3) after Öberg (2011) are represented here by pragmatic (yellow, A) and conceptual (orange, B). Remaining mental models (from group of 13 scientists) were classified as mixed types according to perspective: (C) between epistemological (red) and ontological (violet), (D) pragmatic and conceptual, and (E) conceptual and epistemological. Grey bars show overlap, and shaded grey bars show partial overlap. There can be considerable overlap between the pragmatic (A) and the conceptual (B) perspectives. There is no potential overlap between the pragmatic and the ontological perspectives. Several overlaps occurred between mixed types (D and E), but those differed from AB overlaps. We elicited some overlap between the epistemological and the ontological perspectives, but the number of individuals consulted here was too small to draw any conclusions.

exist, though for very different attributes. We suggest that the graphical profile chart as depicted in Fig. 4 can be used as a tool to identify gaps and overlaps of mental models for all participants of an interdisciplinary research group as a way of speeding up the building of the group's meta-knowledge (van der Bossche et al., 2011) and the awareness of the group members' eventual sharing of a mental model (Carley, 1997).

With this article, we did not aim to maximise the group performance as business and military managers or team scientists using similar methods. We also did not aim to further develop the theory of connectivity, mental models or models of perception in environmental science (e.g. Öberg, 2011). Rather, we intended to encourage natural scientists active in connectivity research to become more familiar with literature on interdisciplinarity and to become aware of the existence of collaboration techniques, such as shared mental model building. Previous studies demonstrated that different or even diverging perspectives do not negatively influence the knowledge creation processes when interactions between the actors are repeated, positively perceived and sufficiently adjusted to encourage relationship building (e.g. Dewulf et al., 2007). The approaches and results of our study have been presented to connectivity scientists in EU COST Action ES1306 and closely discussed with the leaders of the action's working groups in order to facilitate effective communication within the working groups and the network. The principles of mental model analysis were in a different form applied within the collaborative work of EU COST Action ES1306 and led to interdisciplinary studies within (e.g. Connecteur WG3 Think-Tank Team, 2018; Heckmann et al., 2018) and without (e.g. Turnbull et al., 2018) research of connectivity or with actors outside academia (Smetanová et al., 2018).

\section{Conclusions}

The review of current research perspectives and the elicitation of 10 attributes linked to the mental models of scientists active in research on connectivity demonstrated a wide diversity of research philosophies, concepts and methods in the connectivity community. Based on these results, we suggest that a group of interdisciplinary connectivity scientists who have not carried out a mental model elicitation or similar exercise at the beginning of their work (i) is likely to have severe problems of understanding (even if these are not immediately realised), (ii) is unlikely to have useful discussions on the interdisciplinary aspects of connectivity research and (iii) group members will likely waste a lot of time talking past each other. A graphical scheme for shared mental model analysis was introduced to overcome persistent understanding barriers by identifying gaps and overlaps of group perspectives and knowledge. We showed that despite the existing diversity of perspectives and ambitions, overlapping and complementary approaches offer potential for knowledge exchange and knowledge co-production. Though many scholars in the environmental, natural and geosciences have indepth knowledge of, and much experience with, interdisciplinary work, our results suggest that many colleagues might benefit from a shared mental model approach.

Data availability. Data collected in the questionnaires contain private data. They cannot be published under GDPR policy.

Competing interests. The authors declare that they have no conflict of interest. 
Acknowledgements. The think-tank meeting in April 2015 in Berlin was financed by the EU COST Action ES1306 "Connecting European Connectivity Research". The article processing charges for this open-access publication were covered by the Open Access Publication Fund of TU Berlin. Tobias Krueger is funded through IRI THESys, by the German Excellence Initiative. We are thankful to the handling editor Mariano Moreno de las Heras, Genevieve Ali and an anonymous reviewer for their useful comments on the paper.

Edited by: Mariano Moreno de las Heras

Reviewed by: Genevieve Ali and one anonymous referee

\section{References}

Ahlmer, A.-K., Cavalli, M., Hansson, K., Koutsouris, A. J., Crema, S., and Kalantari, Z.: Soil moisture remotesensing applications for identification of flood-prone areas along transport infrastructure, Environ. Earth Sci., 77, 533, https://doi.org/10.1007/s12665-018-7704-z, 2018.

Ali, G., Oswald, C., Spence, C., and Wellen, C.: The t-tel method for assessing water, sediment, and chemical connectivity, Water Resour. Res., 54, 634-662, https://doi.org/10.1002/2017wr020707, 2018.

Baguette, M., Blanchet, S., Legrand, D., Stevens, V. M., and Turlure, C.: Individual dispersal, landscape connectivity and ecological networks, Biol. Rev., 88, 310-326, https://doi.org/10.1111/brv.12000, 2013.

Bracken, L. J. and Croke, J. The concept of hydrological connectivity and its contribution to understanding runoffdominated geomorphic systems, Hydrol. Proc., 21, 1749-1763, https://doi.org/10.1002/hyp.6313, 2007.

Bracken, L. J. and Oughton, E. A.: 'What do you mean?' The importance of language in developing interdisciplinary research, Transactions of the Institute of British Geographers, 31, 371382, https://doi.org/10.1111/j.1475-5661.2006.00218.x, 2006.

Bracken, L. J., Wainwright, J., Ali, G., A., Tetzlaff, D., Smith, M. W., Reaney, S. M., and Roy, A. G.: Concepts of hydrological connectivity: Research approaches, pathways and future agendas, Earth-Sci. Rev., 119, 17-34, https://doi.org/10.1016/j.earscirev.2013.02.001, 2013.

Bracken, L. J., Turnbull, L., Wainwright, J., and Bogaart, P.: Sediment connectivity: a framework for understanding sediment transfer at multiple scales, Earth Surf. Proc. Land., 40, 177-188, https://doi.org/10.1002/esp.3635, 2015.

Brierley, G., Fryirs, K., and Jain, V.: Landscape connectivity: the geographic basis of geomorphic applications, Area, 38, 165-174, https://doi.org/10.1111/j.1475-4762.2006.00671.x, 2006.

Brooks, C. P.: A scalar analysis of landscape connectivity, Oikos, 102, 433-439, 2003.

Callegaro, C. and Ursino, N.: Connectivity of Niches of Adaptation Affects Vegetation Structure and Density in Self-Organized (Dis-Connected) Vegetation Patterns, Land Degrad. Develop., 29, 2589-2594, https://doi.org/10.1002/ldr.2759, 2018.

Carley, K. M.: Extracting team mental models through textual analysis, J. Organiz. Behav., 18, 533-558, 1997.

Cavalli, M., Trevisani, S., Comiti, F., and Marchi, L.: Geomorphometric assessment of spatial sediment connectivity in small Alpine catchments, Geomorphology, 188, 31-41, 2013.
Cilliers, P., Biggs, H. C., Blignaut, S., Choles, A. G., Hofmeyr, J.-H. S., Jewitt, G. P. W., and Roux, D. J.: Complexity, modeling, and natural resource management, Ecol. Soc., 18, 1, https://doi.org/10.5751/ES-05382-180301, 2013.

Clauzel, C., Girardet, X., and Foltête, J. C.: Impact assessment of a high-speed railway line on species distribution: Application to the European tree frog (Hyla arborea) in Franche-Comté, J. Environ. Manag., 127, 125-134, https://doi.org/10.1016/j.jenvman.2013.04.018, 2013.

Connecteur: Cost Action ES 1306: Connecting Connectivity Research, available at: http://connecteur.info (last access: 12 June 2018), 2018.

Connecteur WG 1.: Cost Action ES 1306: Connecting European Connectivity Research: WG Theory development, available at: http://connecteur.info/wiki/connectivity-wiki/ (last access: 14 April 2018), 2018.

Connecteur WG 3 Think-Tank Team (Nunes, J. P., Wainwright, J., Bielders, C. L., Darboux, F., Fiener, P., Finger, D., and Turnbull, L.): Better models are more effectively connected models, Earth Surf. Process. Land., 43, 1355-1360, https://doi.org/10.1002/esp.4323, 2018.

Connecteur WG 5.: Cost Action ES 1306: Connecting European Connectivity Research: WG Transitions of connectivity research towards sustainable land and water management, available at: http://connecteur.info/groups/working-group-5/ (last access: 17 October 2016), 2016.

Cossart, E., Viel, V., Lissak, C., Reulier, R., Fressard, M., and Delahaye, D.: How might sediment connectivity change in space and time?, Land Degrad. Develop., 29, 2595-2613, https://doi.org/10.1002/ldr.3022, 2018.

De Dreu, C. K. W. and Weingart, L. R.: Task versus relationship conflict, team performance, and team member satisfaction: A meta-analysis, J. Appl. Psychol., 88, 741-749, 2003.

Dewulf, A., François, G., Pahl-Wostl, C., and Taillieu, T.: A framing approach to cross-disciplinary research collaboration: experiences from a large-scale research project on adaptive water management, Ecol. Soc., 12, http://www.ecologyandsociety.org/ vol12/iss2/art14/, 2007.

Douglas, E. M., Wheeler, S. A., Smith, D. J., Overton, I. C., Gray, S. A., Doody, T. M., and Crossman, N. D.: Using mentalmodelling to explore how irrigators in the Murray-Darling Basin make water-use decisions, J. Hydrol.: Reg. Stud., 6, 1-12, https://doi.org/10.1016/j.ejrh.2016.01.035, 2016.

Foltête, J. C., Girardet, X., and Clauzel, C.: A methodological framework for the use of landscape graphs in land-use planning, Landscape Urban Plan., 124, 140-150, https://doi.org/10.1016/j.landurbplan.2013.12.012, 2014.

Freeman, M. C., Pringle, C. M., and Jackson, C. R.: Hydrologic connectivity and the contribution of stream headwaters to ecological integrity at regional scales, J. Am. Water Res. Assoc., 43, 5-14, https://doi.org/10.1111/j.1752-1688.2007.00002.x, 2007.

Fryirs, K. A., Brierley, G. J., Preston, N. J., and Kasai, M.: Buffers, barriers and blankets: The (dis)connectivity of catchment-scale sediment cascades, Catena 70, 49-67, https://doi.org/10.1016/j.catena.2006.07.007, 2007.

Gibson, H., Stewart, I. S., Pahl, S., and Stokes, A.: A "mental models" approach to the communication of subsurface hydrology and hazards, Hydrol. Earth Syst. Sci., 20, 1737-1749, https://doi.org/10.5194/hess-20-1737-2016, 2016. 
Godeman, J.: Sustainable Communication as an Inter- and Transdisciplinary Discipline, in: Sustainability Communication: Interdisciplinary Perspectives and Theoretical Foundations, edited by: Godemann, J. and Michelsen, G., Springer Science+Business Media, https://doi.org/10.1007/978-94-007-1697-1, 2011.

Golden, H. E., Creed, I. F., Ali, G., Basu, N. B., Neff, B. P., Rains, M. C., McLaughlin, D. L., Alexander, L. C., Ameli, A. A., Christensen, J. R., Evenson, G. R., Jones, C. N., Lane, C. R., and Lang, M. G.: Integrating geographically isolated wetlands into land management decisions, Front. Ecology Environ., 15, 319327, https://doi.org/10.1002/fee.1504, 2017.

Grabowski, A.: Opinion formation in a social network: The role of human activity, Physica A: Statistical Mechanics and Its Applications, 388, 961-966, https://doi.org/10.1016/j.physa.2008.11.036, 2009.

Hare, M. and Pahl-Wostl, C.: Stakeholder categorisation in participatory integrated assessment processes, Integrated Assessment, 3, 50-62, https://doi.org/10.1076/iaij.3.1.50.7408, 2002.

Harel, M. A. and Mouche, E.: 1-D steady state runoff production in light of queuing theory: Heterogeneity, connectivity, and scale, Water Resour. Res., 49, 7973-7991, https://doi.org/10.1002/2013WR013596, 2013.

Harel, M. A. and Mouche, E.: Is the connectivity function a good indicator of soil infiltrability distribution and runoff flow dimension?, Earth Surf. Proc. Land., 39, 1514-1525, https://doi.org/10.1002/esp.3604, 2014.

Heckmann, T., Cavalli, M., Cerdan, O., Foerster, S., Javaux, M., Lode, E., Smetanová, A., Vericat, D., and Brardinoni, F.: Indices of sediment connectivity, Earth Sci. Rev., 187, 77-108, https://doi.org/10.1016/j.earscirev.2018.08.004, 2018.

Istanbulluoglu, E. and Bras, R. L.: Vegetation-modulated landscape evolution: Effects of vegetation on landscape processes, drainage density, and topography, J. Geophys. Res.-Earth Surf., 110, F02012, https://doi.org/10.1029/2004JF000249, 2005.

Jones, N. A., Ross, H., Lynam, T., Perez, P., and Leitch, A.: Mental Models: An Interdisciplinary Synthesis of Theory and Methods, Ecol. Soc., 16, 46, https://www.ecologyandsociety.org/ vol16/iss 1/art46/, 2011.

Jones, N. A., Ross, H., Lynam, T., and Perez, P.: Eliciting mental models: a comparison of interview procedures in the context of natural resource management, Ecol. Soc., 19, 13, https://doi.org/10.5751/ES-06248-190113, 2014.

Kearney, A. and Kaplan, S.: Toward a Methodology for the Measurement of Knowledge Structures of Ordinary People, Environ. Behav., 29, 579-617, 1997.

Keesstra, S., Nunes, J. P., Saco, P., Parsons, T., Poeppl, R., Masselink, R., and Cerdà, A.: The way forward: Can connectivity be useful to design better measuring and modelling schemes for water and sediment dynamics?, Sci. Total Environ., 644, 15571572, https://doi.org/10.1016/j.scitotenv.2018.06.342, 2018.

Kolkman, M. J., Kok, M., and van der Veen, A.: Mental model mapping as a new tool to analyse the use of information in decisionmaking in integrated water management, Phys. Chem. Earth, 30, 317-332, https://doi.org/10.1016/j.pce.2005.01.002, 2005.

Krueger, T., Maynard, C., Carr, G., Bruns, A., Mueller, E. N., and Lane, S.: A transdisciplinary account of water research, Wiley Interdisciplinary Reviews: Water, 3, 369-389, https://doi.org/10.1002/wat2.1132, 2016.
Leibowitz, S. G., Wigington, P. J., Rains, M. C., and Downing, D. M.: Non-navigable streams and adjacent wetlands: Addressing science needs following the supreme court's rapanos decision, Front. Ecol. Environ., 6, 366-373, https://doi.org/10.1890/070068, 2008.

Ludwig, J. A., Bastin, G. N., Chewings, V. H., Eager, R. W., and Liedloff, A. C.: Leakiness: a new index for monitoring the health of arid and semiarid landscapes using remotely sensed vegetation cover and elevation data, Ecol. Indic., 7, 442-454, https://doi.org/10.1016/j.ecolind.2006.05.001, 2007.

Lynam, T. and Brown, K.: Mental Models in Human-Environment Interactions: Theory, Policy Implications, and Methodological Explorations, Ecol. Soc., 17, 3, https://doi.org/10.5751/ES04257-170324, 2012.

Lynam, T., Mathevet, R., Etienne, M., Stone-Jovicich, S., Leitch, A., Jones, N., Ross, H., Du Toit, D., Pollard, S., Biggs, H., and Perez, P.: Waypoints on a Journey of Discovery: Mental Models in Human-Environment Interactions, Ecol. Soc., 17, 3, https://doi.org/10.5751/ES-05118-170323, 2012.

Manjunath, K. and Mohan, M. R.: A new hybrid multi-objective quick service restoration technique for electric power distribution systems, Int. J. Electrical Power \& Energy Systems, 29, 51-64, https://doi.org/10.1016/j.ijepes.2005.12.012, 2007.

Mohammed, S., Klimoski, R., and Rentsch, J. R.: The Measurement of Team Mental Models: We Have No Shared Schema, Organizational Research Methods, 3, 123-165, https://doi.org/10.1177/109442810032001, 2000.

Mueller, E. N., Wainwright, J., and Parsons, A. J.: The stability of vegetation boundaries and the propagation of desertification in the American Southwest: A modelling approach, Ecol. Model., 208, 91-101, https://doi.org/10.1016/j.ecolmodel.2007.04.010, 2007.

Mykura, N. ST4120: Somerset Levels Lower Burrow and flooding on West Moor, available at: http://www.geograph.org.uk/photo/ 1136561 (last access: 22 August 2018), 2018.

Nadeau, T. L. and Rains, M. C.: Hydrological connectivity between headwater streams and downstream waters: How science can inform policy, J. Am. Water Res. Assoc., 43, 118-133, https://doi.org/10.1111/j.1752-1688.2007.00010.x, 2007.

Neumann, R. B. and Cardon, Z. G.: The magnitude of hydraulic redistribution by plant roots: a review and synthesis of empirical and modelling studies, New Phytol., 194, 337-352, https://doi.org/10.1111/j.1469-8137.2012.04088.x, 2012.

Öberg, G.: Interdisciplinary Environmental Studies: A Primer. Wiley-Blackwell, 184 pp., 2011.

Pahl-Wostl, C. and Hare, M.: Processes of social learning in integrated resources management, J. Comm. Appl. Soc. Psychol., 14, 193-206, https://doi.org/10.1002/casp.774, 2004.

Prager, K. and Curfs, M.: Using mental models to understand soil management, Soil Use Manage. 32, 36-44, https://doi.org/10.1111/sum.12244, 2016.

Parsons, A. J., Bracken, L., Poeppl, R. E., Wainwright, J., and Keesstra, S. D.: Introduction to special issue on connectivity in water and sediment dynamics, Earth Surf. Process. Land., 40, 1275-1277, https://doi.org/10.1002/esp.3714, 2015.

Poeppl, R. E. and Parsons, A. J.: The geomorphic cell: a basis for studying connectivity, Earth Surf. Process. Land., 43, 11551159, https://doi.org/10.1002/esp.4300, 2017. 
Prieto, I., Armas, C., and Pugnaire, F. I.: Water release through plant roots: new insights into its consequences at the plant and ecosystem level, New Phytol., 193, 830-841, https://doi.org/10.1111/j.1469-8137.2011.04039.x, 2012.

Smetanová, A. and Dąbrowska, K.: Language of geomorphology, XII EGEA Eastern Regional Congress 2009, Jastrzebia Gora (31.3-4.4.2009), EGEA Warsaw \& Warsaw university, 32-37, 2009.

Smetanová, A., Paton, E., Maynard, C., Tindale, S., FernándezGetino, S. P., Marqéus Pérez, M. J., Bracken, L., Le Bissonnais, Y., and Keesstra, S. D.: Stakeholders' perception of the relevance of water and sediment connectivity in water and land management, Land Degrad. Develop., 29, 1833-1844, https://doi.org/10.1002/ldr.2934, 2018.

Smith-Jentsch, K. A., Cannon-Bowers, J. A., Tannenbaum, S. I., and Salas, E. Guided team self-correction - Impacts on team mental models, processes, and effectiveness, Small Group Research, 39, 303-327, https://doi.org/10.1177/1046496408317794, 2008.

Stam, C. J., van Straaten, E. C. W., Van Dellen, E., Tewarie, P., Gong, G., Hillebrand, A., Meier, J., and Van Mieghem, P.: The relation between structural and functional connectivity patterns in complex brain networks, Int. J. Psychophysiol., 103, 149-160, https://doi.org/10.1016/j.ijpsycho.2015.02.011, 2016.

Tannier, C., Bourgeois, M., Houot, H., and Foltête, J. C.: Impact of urban developments on the functional connectivity of forested habitats: a joint contribution of advanced urban models and landscape graphs, Land Use Policy, 52, 76-91, https://doi.org/10.1016/j.landusepol.2015.12.002, 2016.
Tetzlaff, D., Soulsby, C., Bacon, P. J., Youngson, A. F., Gibbins, C., and Malcolm, L. A. Connectivity between landscapes and riverscapes - a unifying theme in integrating hydrology and ecology in catchment science?, Hydrol. Process., 21, 1385-1389, https://doi.org/10.1002/hyp.6701, 2007.

Thomson Klein, J. T.: Interdisciplinary teamwork: The Dynamics of collaboration and integration, in: Interdisciplinary collaboration: An emerging cognitive science, edited by: Derry, S., Schunn, C. D., and Gernsbacher, M. A., Mahwah: Erlbaum, 23-50, 2005.

Turnbull, L., Hütt, M.-T., Ioannides, A. A., Kininmonth, S., Poeppl, R., Tockner, K., Bracken, L. J., Keesstra, S., Liu, L., Masselink, R., and Parsons, A. J.: Connectivity and complex systems: learning from a multi-disciplinary perspective, Appl. Network Sci., 3, 11, https://doi.org/10.1007/s41109-018-0067-2, 2018.

van den Bossche, P., Gijselaers, W., and Segers, M.: Team learning: building shared mental models, Instructional Science, 39, 283, https://doi.org/10.1007/s11251-010-9128-3, 2011.

Vericat, D.: Disconnecting sediment and water fluxes, available at: http://connecteur.info/connecteur-image-archive/ (last access: 22 August 2018), 2015.

Wainwright, J., Turnbull, L., Ibrahim, T. G., Lexartza-Artza, I., Thomton, S. F., and Brazier, R. E.: Linking Environmental Régimes, Space and Time: Interpretations of Structural and Functional Connectivity, Geomorphology, 126, 387-404, https://doi.org/10.1016/j.geomorph.2010.07.027, 2011. 